\title{
Controlling schistosomiasis: the cost-effectiveness of alternative delivery strategies
}

\author{
HELEN GUYATT, ${ }^{1}$ DAVID EVANS,${ }^{2}$ CHRISTIAN LENGELER ${ }^{3}$ AND MARCEL TANNER ${ }^{1}$ \\ 'Department of Public Health and Epidemiology, Swiss Tropical Institute, Basel, Switzerland, 'Special \\ Programme for Research and Training in Tropical Diseases, World Health Organization, Geneva,

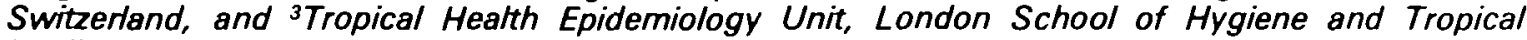 \\ Medicine, UK.
}

\begin{abstract}
Sustainable schistosomiasis control cannot be based on large-scale vertical treatment strategies in most endemic countries, yet little is known about the costs and effectiveness of more affordable options. This paper presents calculations of the cost-effectiveness of two forms of chemotherapy targeted at schoolchildren and compares them with chemotherapy integrated into the routine activities of the primary health care system. The focus is on Schistosome haematobium. Economic and epidemiological data are taken from the Kilombero District of Tanzania. The paper also develops a framework for possible use by programme managers to evaluate similar options in different epidemiological settings. The results suggest that all three options are more affordable and sustainable than the vertical strategies for which cost data are available in the literature. Passive testing and treatment through primary health facilities proved the most effective and cost-effective option given the screening and compliance rates observed in the Kilombero District.
\end{abstract}

\section{Introduction}

It is now generally accepted that most of the endemic countries in sub-Saharan Africa are unable to sustain large-scale vertical schistosomiasis control programmes from their own resources (Evans 1992; Guyatt and Evans 1992). The search for more affordable yet effective options has focused on two forms of chemotherapy aimed at morbidity reduction. The first involves targeting treatment at high-risk groups such as school-children; the second involves integrating chemotherapy into the day to day activities of the primary health care system (Gryseels 1989; Tanner 1989). However, virtually no data are available on the costs and effectiveness of these options. The first purpose of this paper, then, is to estimate the likely costs and coverage under three possible variations of these strategies.

The second purpose is to develop a methodology which may be generally applicable to such planning exercises. One problem with the existing studies on the costs of chemotherapy pro- grammes in schistosomiasis control (for example, Korte et al. 1986; Brinkmann et al. 1988; Jobin 1989; Rohde 1989) is that the methodologies used have been unclear - details of the items included as costs and the way they were measured are rarely provided, for example. A consistent format for estimating costs is required to allow consistent comparisons of the different options and an evaluation of how variations in economic and epidemiological data affect the relative attractiveness of the options (Reynolds and Gaspari 1985; Bundy and Guyatt 1992). A step-by-step cost analysis illustrating how economic and epidemiological data can be used to evaluate alternative control options at the district level is, therefore, presented. The methodology would also be appropriate to smaller administrative units of an endemic area.

Two of the options considered are targeted at school-children, believed to be a high-risk group which is relatively accessible to chemotherapy programmes. The third provides screening and treatment at primary health care facilities, 
available to anyone who requests it. Clearly the target population differs in the third option, reflecting the sort of choices planners face in choosing between targeted control and delivery through the primary health care system. The analysis focuses on Schistosoma haematobium and is based on actual economic and epidemiological data collected from surveys and control interventions in the Kilombero District of Tanzania.

\section{Methods}

\section{Study area}

The Kilombero District is in the Morogoro Region, south-eastern Tanzania, and has been described in detail elsewhere (Tanner et al. 1987; Tanner et al. 1991). The population according to the 1988 national census was 187000 , and 22108 children were enrolled in the 77 primary schools (Lengeler et al. 1991a). The District contained one District Hospital at Ifakara, two Rural Health Centres, 13 Government and 7 Mission dispensaries. Most of the dispensaries are poorly equipped and have no electricity, materials or drugs required for schistosomiasis testing and treatment. In particular, most dispensaries do not have a microscope in working order (Gilson 1992).

Urinary schistosomiasis is endemic in most villages, though infection prevalence varies widely between sites. The average infection prevalence observed from surveys of schoolchildren was $21 \%$ (median: $12.5 \%$ ), but reached $70-80 \%$ in some schools (Lengeler et al. 1991a).

The high and widespread endemicity of schistosomiasis in this area has stimulated a number of research and control projects (Tanner et al. 1991), mostly initiated by the Ifakara Centre (former Swiss Tropical Institute Field Laboratory) and the Swiss Tropical Institute in Basel. Two in particular provide data for the current analysis. The first was undertaken between 1986 and 1987 in Kilombero, and in 1988 in the neighbouring Kilosa District. As part of this study, most schools in the Kilombero District were surveyed for schistosomiasis by a mobile team (Lengeler et al. 1991a) and the use of teachers in reagent strip testing of schoolchildren was investigated in Kilosa District
(Lengeler et al. 1991b). The second study is part of the ongoing Communicable Disease Control project based at the Ifakara Centre with close collaboration with the District Medical Officer and the District Education Officer. As part of this project, 4 dispensaries serving communities of high prevalence were provided with the trained personnel, equipment and drugs necessary for the diagnosis and treatment of schistosomiasis as part of their routine activities.

The epidemiological and economic data from these studies, and some additional data obtained from the District Medical Officer, District Education Office and Accounting Department at the Ifakara Centre, have been used as baseline data for the analysis of the comparative costs and coverage achieved by the three distribution strategies: 1) annual mass treatment of schoolchildren by a mobile team, 2) annual reagent strip testing of school-children by teachers and referral to the dispensary for treatment, and 3 ) passive testing and treatment at the dispensary level.

\section{Description of control alternatives}

Mass treatment by a mobile team (MMT)

This option involves the annual mass treatment of all primary school-children by a mobile team comprising one driver, one fieldworker and one Rural Medical Aid. All 77 schools are visited and all children present are treated with a single oral dose of praziquantel $(40 \mathrm{mg} / \mathrm{kg})$. Transport is provided by a rented vehicle. The mobile team (excluding the driver) undergo annual training at the Ifakara Centre under the guidance of a Medical Assistant. In some situations it would be more efficient to screen schools before treating only the positives; the extra costs of screening would be more than offset by reduced costs of treatment. The level of prevalence at which it is better to screen before treatment has been discussed elsewhere (Prescott 1987), and for the purposes of this exercise it is assumed that no prior screening is undertaken. It might also be preferable in some circumstances to treat only schools known or believed to have high prevalences of infection. The implications of choosing this option will be considered in a subsequent paper, but here the implications of mass treating all schools in a given geographical area will be considered. 
Reagent strip testing by school teachers (RST)

In this option teachers annually screen children using Sangur reagent strips (Boehringer, Mannheim, FRG) and refer all positives to the nearest dispensary for treatment. One teacher per school attends a workshop for training in reagent strip testing, where they also receive health education and materials required for screening their school. The workshop team consists of one expert, two fieldworkers and one driver. Transport is provided by a rented vehicle. Training the teachers involves the use of 10 reagent strips per teacher. The programme is supervised by a Medical Assistant making annual visits to all schools as part of a routine supervisory visit to the local health facilities. The visits aim at motivating teachers and preparing them for the next round of screening and treatment.

\section{Passive testing and treatment at the dispensary (PTT)}

Control is provided by passive case detecting using urine sedimentation and subsequent treatment of positives with a single oral dose of praziquantel $(40 \mathrm{mg} / \mathrm{kg})$. This requires the provision of trained staff and equipment for screening and treatment at all dispensaries (including the two Health Centres). All dispensaries are provided with a microscope and one person from each dispensary is trained to perform the diagnostic technique. Training involves a one-day workshop at facility level in each division. Each workshop team consists of one expert, two Medical Assistants, one District Health Officer and one driver. Transport for the workshop team is provided by a rented vehicle. All materials utilized in training form part of the bulk package given to each dispensary. This basic diagnostic package consists of 1 bucket, 20 urine containers, 20 urine sedimentation containers, 100 slides, 1000 coverslips, 4 litres of disinfectant and 10 pasteur pipettes and teats. Supervision is undertaken by a Medical Assistant who visits each dispensary twice a year, their transport being provided by a rented vehicle and a driver.

\section{Data sources}

Salaries and per diems of teachers were obtained from the District Education Office; those for dispensary workers (Rural Medical Aids, Medical Assistants and laboratory technicians) and the District Health Officer were obtained from the District Medical Office. The Accoun- ting Office at the Ifakara Centre provided details of salaries and per diems for fieldworkers, drivers and experts (based on Tanzanian parastatal salary scales), as well as information on vehicle rental and running costs. Microscope purchase prices (including freight) were provided by Tropical Health Technology (Cambridgeshire, England). The Communicable Disease Control project (Ifakara Centre) provided costs for all dispensary screening materials, while the costs of screening materials for reagent strip testing were taken from Lengeler et al. (1991b).

Productivity of personnel in performing tasks at the dispensaries was based on experience in the Communicable Disease Control project and observation at the dispensaries. An estimate of the cost of praziquantel was obtained from UNICEF (UNICEF Supply Division, Freeport, DK-2100 Copenhagen) and includes freight costs. Demographic data were based on the 1988 census and attendance rates at school were provided by the District Education Office. The prevalence of infection at each school was taken from Lengeler (1989).

\section{Unit cost menu}

In this analysis, the health care provider's perspective is taken by estimating the extra financial costs inherent in each option. The full costs of hiring new staff, for example, are included in this financial analỳsis. The time of existing staff who are diverted to a control option is recorded separately and multiplied by the official wage to provide an idea of the opportunity cost of diverting staff. Although these staff are already being paid, and their involvement in the programme imposes no extra financial costs on the provider, the need to divert the time of skilled staff is likely to influence the assessment from the provider's viewpoint. Accordingly, these opportunity costs are added to the financial costs and the sum is called the 'economic costs', recognizing that some of the prices used in the calculations may not reflect true economic or shadow prices.

The itemized cost data for each strategy is given in Tables la-c. The cost menu is designed to be simple enough for field use by programme managers, whilst flexible enough to incorporate some of the more complex issues of costing. Each item is categorized under the headings Personnel, Vehicle, Consumables and Capital items. 
The units for each item are identified and the unit costs are further classified under the activity classes of Supervision, Training, Screening and Treatment. For the purposes of this analysis, all costs are reported in 1991 US dollars. Personnel and transport costs are initially paid in local currency (Tsh) and converted to US\$ using the official exchange rate of 250 Tsh per US\$ (average 1991 exchange rate from the Bank of Tanzania).
For budgeting purposes it can be important to consider domestic and foreign exchange costs separately. The cost menus presented here can be easily adapted for this.

The only financial costs for salaries are for the Ifakara Centre staff (i.e. driver, fieldworkers and expert). In addition to their salaries, per diems are paid to all staff employed by the pro-

Table 1. Unit cost menu for (a) mass treatment by the mobile team (MMT), (b) reagent strip testing by teachers (RST) and (c) passive testing and treatment at the dispensary (PTT) (a)

\begin{tabular}{|c|c|c|c|c|}
\hline \multirow[t]{2}{*}{ Category } & \multirow[t]{2}{*}{ Item } & \multirow[t]{2}{*}{ Units } & \multicolumn{2}{|c|}{ Unit cost (US\$) } \\
\hline & & & Training & Treatment \\
\hline Personnel & $\begin{array}{l}\text { Driver's salary } \\
\text { Driver's per diem } \\
\text { Fieldworker's salary } \\
\text { Fieldworker's per diem } \\
\text { RMA's salary } \\
\text { RMA's per diem } \\
\text { MA's salary } \\
\text { MA's per diem }\end{array}$ & $\begin{array}{l}\text { per day } \\
\text { per day } \\
\text { per day } \\
\text { per day } \\
\text { per day } \\
\text { per day } \\
\text { per day } \\
\text { per day }\end{array}$ & $\begin{array}{r}\cdots \\
\cdots \\
2 \\
12 \\
1.2 \\
10.4 \\
1.6 \\
10.4\end{array}$ & $\begin{array}{r}2 \\
12 \\
2 \\
12 \\
1.2 \\
10.4 \\
\cdots \\
\cdots\end{array}$ \\
\hline Vehicle & $\begin{array}{l}\text { Running costs } \\
\text { Rental }\end{array}$ & $\begin{array}{l}\text { per km } \\
\text { per } \mathrm{km}\end{array}$ & $\begin{array}{l}0.25 \\
0.48\end{array}$ & $\begin{array}{l}0.25 \\
0.48\end{array}$ \\
\hline Consumables & Drug & per child & $\ldots \ldots$ & 0.66 \\
\hline
\end{tabular}

(b)

\begin{tabular}{|c|c|c|c|c|c|c|}
\hline \multirow[t]{2}{*}{ Category } & \multirow[t]{2}{*}{ Item } & \multirow[t]{2}{*}{ Units } & \multicolumn{4}{|c|}{ Unit cost (USS) } \\
\hline & & & Supervision & Training & Screening & Treatment \\
\hline Personnel & $\begin{array}{l}\text { Driver's salary } \\
\text { Driver's per diem } \\
\text { Expert's salary } \\
\text { Expert's per diem } \\
\text { Fieldworker's salary } \\
\text { Fieldworker's per diem } \\
\text { Teacher's salary } \\
\text { Teacher's per diem } \\
\text { RMA's salary } \\
\text { MA's salary } \\
\text { MA's per diem }\end{array}$ & $\begin{array}{l}\text { per day } \\
\text { per day } \\
\text { per day } \\
\text { per day } \\
\text { per day } \\
\text { per day } \\
\text { per day } \\
\text { per day } \\
\text { per day } \\
\text { per day } \\
\text { per day }\end{array}$ & $\begin{array}{c}2 \\
12 \\
\cdots \cdots \\
\cdots \cdots \\
\cdots \cdots \\
\cdots \cdots \\
\cdots \cdots \\
\cdots \cdots \\
1.6 \\
10.4\end{array}$ & $\begin{array}{c}2 \\
12 \\
4 \\
18 \\
2 \\
12 \\
1.8 \\
10.4 \\
\cdots \\
\cdots \\
\cdots\end{array}$ & $\begin{array}{l}\cdots \cdots \\
\cdots \cdots \\
\cdots \cdots \\
\cdots \cdots \\
\cdots \cdots \\
\cdots \cdots \\
1.8 \\
\cdots \cdots \\
\cdots \cdots \\
\cdots \cdots \\
\cdots \cdots\end{array}$ & $\begin{array}{l}\cdots \cdots \\
\cdots \cdots \\
\cdots \cdots \\
\cdots \cdots \\
\cdots \cdots \\
\cdots \cdots \\
\cdots \cdots \\
\ldots \ldots \\
1.2 \\
\cdots \cdots \\
\cdots \cdots\end{array}$ \\
\hline Vehicle & $\begin{array}{l}\text { Running costs } \\
\text { Rental }\end{array}$ & $\begin{array}{l}\text { per } \mathrm{km} \\
\text { per } \mathrm{km}\end{array}$ & $\begin{array}{l}0.25 \\
0.48\end{array}$ & $\begin{array}{l}0.25 \\
0.48\end{array}$ & $\ldots$ & a... \\
\hline Consumables & $\begin{array}{l}\text { Reagent strips } \\
\text { Urine pots } \\
\text { Record card } \\
\text { Drug }\end{array}$ & $\begin{array}{l}\text { per person } \\
\text { per child } \\
\text { per child } \\
\text { per child }\end{array}$ & $\begin{array}{l}\cdots \cdots \\
\cdots \cdots \\
\cdots \cdots \\
\cdots \cdots\end{array}$ & $\begin{array}{c}2 \\
\ldots \\
\cdots \cdots \\
\cdots \cdots\end{array}$ & $\begin{array}{l}0.2 \\
0.042 \\
\ldots \ldots \\
\ldots \ldots\end{array}$ & $\begin{array}{l}\ldots \ldots \\
\ldots .01 \\
0.06\end{array}$ \\
\hline
\end{tabular}


(c)

\begin{tabular}{|c|c|c|c|c|c|c|}
\hline \multirow[t]{2}{*}{ Category } & \multirow[t]{2}{*}{ Item } & \multirow[t]{2}{*}{ Units } & \multicolumn{4}{|c|}{ Unit cost (USS) } \\
\hline & & & Supervision & Training & Screening & Treatment \\
\hline Personnel & $\begin{array}{l}\text { Driver's salary } \\
\text { Driver's per diem } \\
\text { Expert's salary } \\
\text { Expert's per diem } \\
\text { Health Officer's salary } \\
\text { Health Officer's per diem } \\
\text { MA's salary } \\
\text { MA's per diem } \\
\text { Lab. technician's salary } \\
\text { Lab. technician's per diem } \\
\text { RMA's salary }\end{array}$ & $\begin{array}{l}\text { per day } \\
\text { per day } \\
\text { per day } \\
\text { per day } \\
\text { per day } \\
\text { per day } \\
\text { per day } \\
\text { per day } \\
\text { per day } \\
\text { per day } \\
\text { per day }\end{array}$ & $\begin{array}{r}2 \\
12 \\
\cdots \cdots \\
\cdots \cdots \\
\cdots \cdots \\
\cdots . . \\
1.6 \\
10.4 \\
\cdots \cdots \\
\cdots \cdots \\
\cdots \cdots\end{array}$ & $\begin{array}{r}2 \\
12 \\
4 \\
18 \\
6 \\
10.4 \\
1.6 \\
10.4 \\
0.8 \\
10.4 \\
\cdots . .\end{array}$ & $\begin{array}{l}\cdots \cdots \\
\cdots \cdots \\
\cdots \cdots \\
\cdots \cdots \\
\cdots \cdots \\
\cdots \cdots \\
\cdots \cdots \\
\cdots \cdots \\
\cdots . . \\
\cdots \cdots \\
1.2\end{array}$ & $\begin{array}{l}\cdots \cdots \\
\cdots \cdots \\
\cdots \cdots \\
\cdots \cdots \\
\cdots \cdots \\
\cdots \cdots \\
\cdots \cdots \\
\cdots \cdots \\
\cdots \cdots \\
\cdots \cdots \\
1.2\end{array}$ \\
\hline Vehicle & $\begin{array}{l}\text { Running costs } \\
\text { Rental }\end{array}$ & $\begin{array}{l}\text { per } \mathbf{k m} \\
\text { per } \mathbf{k m}\end{array}$ & $\begin{array}{l}0.25 \\
0.48\end{array}$ & $\begin{array}{l}0.25 \\
0.48\end{array}$ & $\begin{array}{l}\ldots . . \\
\cdots . .\end{array}$ & $\begin{array}{l}\cdots . . \\
\cdots \cdots\end{array}$ \\
\hline Consumables & $\begin{array}{l}\text { Slides } \\
\text { Coverslips } \\
\text { Disinfectant } \\
\text { Pasteur pipettes and teats } \\
\text { Drug }\end{array}$ & $\begin{array}{l}\text { per dispensary } \\
\text { per dispensary } \\
\text { per dispensary } \\
\text { per dispensary } \\
\text { per dispensary }\end{array}$ & $\begin{array}{l}\cdots . . \\
\cdots \cdots \\
\cdots \cdots \\
\cdots \cdots \\
\cdots \cdots\end{array}$ & $\begin{array}{l}\cdots . . \\
\cdots . . \\
\cdots . . \\
\cdots \cdots \\
\cdots . .\end{array}$ & $\begin{array}{c}6.08 \\
17.48 \\
32 \\
7.98 \\
\cdots .\end{array}$ & $\begin{array}{l}\cdots . . \\
\cdots . . \\
\cdots \cdots \\
\ldots . . \\
0.99\end{array}$ \\
\hline $\begin{array}{l}\text { Capital } \\
\text { items* }\end{array}$ & $\begin{array}{l}\text { Microscope } \\
\text { Bucket } \\
\text { Urine containers } \\
\text { Urine sedimentation } \\
\text { containers }\end{array}$ & $\begin{array}{l}\text { per dispensary } \\
\text { per dispensary } \\
\text { per dispensary } \\
\text { per dispensary }\end{array}$ & $\begin{array}{l}\cdots \cdots \\
\cdots \cdots \\
\cdots \cdots \\
\cdots \cdots\end{array}$ & $\begin{array}{l}\cdots \cdots \\
\cdots \cdots \\
\cdots \cdots \\
\cdots \cdots\end{array}$ & $\begin{array}{c}1486.35 \\
4 \\
3.04 \\
7.6\end{array}$ & $\begin{array}{l}\cdots . . \\
\cdots . . \\
\cdots \cdots \\
\cdots \cdots\end{array}$ \\
\hline
\end{tabular}

* indicates purchase price; these are annualized in the cost analysis

RMA = Rural Medical Aid, MA = Medical Assistant.

ject for their time in the field, and to all existing personnel spending time away from home for training workshops, etc.

The only capital expenditures included occur at the dispensary level. The annualized cost of a microscope is calculated using a life expectancy of 10 years and an interest rate of $10 \%$. The reusable items utilized for screening are assumed to have a life expectancy of 3 years. Since the microscope will not only be used for schistosomiasis control, this represents the worst possible case for the cost of the passive detection and treatment (PTT) option. No new buildings would be required for any of the control options; a small part of existing space will be diverted occasionally, but this is not likely to influence the provider's decision as it does not prevent other activities being undertaken. The initial training workshops for dispensary workers and teachers are considered to be capital outlays with a life expectancy of 3 years, and thus are annualized over this time period using an interest rate of $10 \%$.

Praziquantel was available at US\$282 per 1000 tablets of $600 \mathrm{mg}$. Including airfreight costs (US\$ 175 for 4000 tablets (WHO)), one tablet costs US\$ 0.33. For treating children, it is assumed that 2 tablets are required per child at a cost per dose of US\$ 0.66 for the mobile team and reagent strip testing and treatment options. In the dispensary option both adults and children are treated and thus it is assumed that on average 3 tablets per dose are required, giving a cost per dose of US\$ 0.99 . In many situations, patients would be required to meet some of the costs, and although this could be incorporated in the menus, this analysis assumes all costs are met by the programme. The price of praziquantel seems to vary not only by supplier, but also by 
customer, and over time for any supplier. The impact of such variations is considered in the sensitivity analysis.

\section{Economic parameters}

\section{Mass treatment by a mobile team (MMT)}

Field experience suggests that the mobile team can cover 2 schools per day. Allowing for travel time, the District could be covered in 45 working days. This would involve travelling $1000 \mathrm{~km}$ to reach all the schools in the District. Annual training would involve 2 days at the Ifakara Centre.

\section{Reagent strip testing by school teachers (RST)}

Each workshop would take one day and 4 workshops would be required to cover the whole district (one each in Ifakara, Mlimba, Mngeta and Mang'ula). Including travel time, the workshop team would be required for 7 days, and would travel $500 \mathrm{~km}$ to reach all workshop destinations. Screening by teachers should only take place between $10 \mathrm{am}$ and $2 \mathrm{pm}$ due to the circadian variation of haematuria (Lengeler et al. 1991c), and one teacher could screen 100 children during this time period. This time taken represents approximately half of a normal working day. In a full working day the Rural Medical Aid at the dispensary could treat 120 children referred to the dispensary. Supervisory visits by the Medical Assistant are assumed to take one sixth of the time of a regular visit to the neighbouring health facilities.

\section{Passive testing and treatment at the dispensary} (PTT)

As in the RST option, each training workshop would take one day, with 4 workshops for the whole district. Again, the workshop team would be required for 7 days and would travel $500 \mathrm{~km}$. A patient attending the dispensary would firstly be received by the Rural Medical Aid for a consultation taking approximately 5 minutes. A urine sample would be taken and the diagnostic test would take approximately 10 minutes. For a positive test the patient would receive a prescription and treatment from the Rural Medical Aid taking approximately 4 minutes. The Medical Assistant visits all health facilities twice a year, spending one day at each dispensary per visit. Travel to all dispensaries for one round of visits encompasses $1000 \mathrm{~km}$. Supervision for schisto- somiasis control is assumed to take one third of the time of a regular supervisory visit.

\section{Epidemiological and demographic parameters}

Mass treatment by a mobile team (MMT)

For each of the 77 schools, the number of children registered and the prevalence of infection is known. Using the $82 \%$ attendance rate of registered students provided by the District Education Office, a total of 18094 children would be present on any given day and 3495 of them would be infected. Past experience in the area suggests it is reasonable to assume that $100 \%$ comply with treatment by the mobile team, although lower levels of compliance could be built into the calculations.

\section{Reagent strip testing by school teachers (RST)}

If $100 \%$ of children complied with the reagent strip testing, 18094 would be screened. Given that the test is $75.4 \%$ sensitive and $88.7 \%$ specific (Lengeler 1989), and assuming a compliance for treatment of $90 \%, 3856$ children would be treated under this option, of whom 2372 would be infected.

Passive testing and treatment at the dispensary (PTT)

Data from the Communicable Disease Control project indicate that approximately $11 \%$ of the total population are screened in one year through the routine activities of dispensaries. The denominator used in this calculation was the total population including school-children. However, the numerator did not include schoolchildren who were treated separately in the project. If they are assumed to present at dispensaries in the same proportion as the rest of the population, approximately $16 \%$ of the total population (29 920 people) would be screened at the dispensaries in any given year. Data from the Communicable Disease Control project also show that $40 \%$ of those screened for urinary schistosomiasis at dispensaries were positive and $60 \%$ negative, suggesting that 11968 of the 29920 persons screened would be infected. If between $10-15 \%$ of the overall population is infected (a realistic estimate based on the known $21 \%$ of school-children who are infected), then between $43-64 \%$ of the infected population would be screened at the dispensaries each year. 
It is important to note that the target group for PTT is the entire population, whereas RST and MMT target only school-children. The rationale for this difference in target group is that both RST and MMT are only suitable for targeting at children, because firstly, the specificity of RST in adults is low and secondly, a test and treat campaign using MMT which includes the adult population involves operational problems in reaching them. PTT is an option available to the entire population and it would be unethical to confine this service only to the children. In this present example, RST treats 2372 infected children, MMT treats 3495 infected children and PTT treats 11968 infected children and adults. The relatively low number of infected children treated through the school-based approaches (RST and MMT) is due largely to the low school registration rates in the area (approximately $50 \%)$.

\section{Results}

Details of the unit prices used in the cost calculations are provided in Table 1 . The total cost of each alternative for one year, the total number of infected people treated, and the cost per infected person treated under the three options are found in Table 2. Total financial and economic costs are both presented, the latter defined as the financial costs plus the opportunity costs of utilizing existing personnel. Both the financial and economic costs produce similar qualitative results. RST is the least costly and PTT is the most expensive. The opposite ranking occurs in terms of effectiveness, with PTT resulting in the most infected people being treated, and RST in the least. The implications of these results for control are complex.
Take the choice between MMT and RST, both delivered through schools. The more efficient option in terms of the cost per infected person treated would be RST, which would also be approximately $\$ 7000$ cheaper than MMT on a district wide basis. However, 1123 fewer infected children would be treated using RST. The control programme must decide whether it is worth spending the extra $\$ 7000$ to treat an extra 1123 children. This is a value judgement, and other possible uses of the $\$ 7000$ would have to be taken into account at least implicitly.

The PTT option is even more expensive, but results in a very large increase in effectiveness, with many more infected people treated. However, this option is likely to be divisible in the sense that it could be applied to only part of the District if necessary. For example, with reference to Table 2, assume that the control programme has decided it is worth spending the extra funds on MMT, in which case 3495 children could be treated for $\$ 15663$. The same total expenditure could result in 8798 infected people being treated through dispensaries (PTT) simply by restricting the availability of testing and treatment to $73.5 \%$ (15 663/21 307) of the district. A similar argument applies to the comparison between RST and PTT: for the $\$ 8803$ required by RST, 4945 infected people could be treated by restricting the availability of PTT to $41.3 \%$ $(8803 / 21307)$ of the district. Reducing the scope of PTT therefore allows more infected people to be treated than either MMT or RST, at no extra cost. As long as it is divisible, PTT is the preferred option.

It is possible that decision-makers would not be willing to divide the PTT option in this way.

Table 2. Comparison of the cost and cost-effectiveness of the three control options in the first year

\begin{tabular}{llccc}
\hline & & $\begin{array}{c}\text { Mass treatment by a } \\
\text { mobile team (MMT) }\end{array}$ & $\begin{array}{c}\text { Reagent strip testing } \\
\text { by teachers (RST) }\end{array}$ & $\begin{array}{c}\text { Passive testing and treatment } \\
\text { at dispensaries (PTT) }\end{array}$ \\
\hline Total cost (USS) & $\begin{array}{l}\text { Financial } \\
\text { Economic }\end{array}$ & 15663 & 8803 & 21307 \\
& 15723 & 9072 & 22430 \\
$\begin{array}{l}\text { Number of infected } \\
\text { persons treated }\end{array}$ & & 3495 & 2372 & 11968 \\
$\begin{array}{l}\text { Cost per infected } \\
\text { person treated (USS) }\end{array}$ & $\begin{array}{l}\text { Financial } \\
\text { Economic }\end{array}$ & 4.48 & 3.71 & 1.78 \\
\hline
\end{tabular}


Table 3. The percentage distribution of costs by input category and activity

\begin{tabular}{|c|c|c|c|c|}
\hline & & $\begin{array}{l}\text { Mass treatment by a } \\
\text { mobile team (MMT) }\end{array}$ & $\begin{array}{l}\text { Reagent strip testing } \\
\text { by teachers (RST) }\end{array}$ & $\begin{array}{c}\text { Passive testing and treatment } \\
\text { at dispensaries (PTT) }\end{array}$ \\
\hline $\begin{array}{l}\text { Input } \\
\text { categories }\end{array}$ & $\begin{array}{l}\text { Personnel (opp. salaries) } \\
\text { Personnel (fin. salaries) } \\
\text { Personnel (fin. allow.) } \\
\text { Vehicle } \\
\text { Supplies (excl. drugs) } \\
\text { Drug }\end{array}$ & $\begin{array}{l}0.4 \% \\
1.2 \% \\
10.3 \% \\
4.6 \% \\
\text { n.a. } \\
83.5 \%\end{array}$ & $\begin{array}{l}3.0 \% \\
0.5 \% \\
7.0 \% \\
4.3 \% \\
54.3 \% \\
30.9 \%\end{array}$ & $\begin{array}{r}5.0 \% \\
0.2 \% \\
2.7 \% \\
2.8 \% \\
31.2 \% \\
58.1 \%\end{array}$ \\
\hline $\begin{array}{l}\text { Activity } \\
\text { categories }\end{array}$ & $\begin{array}{l}\text { Supervision } \\
\text { Training } \\
\text { Screening } \\
\text { Treatment }\end{array}$ & $\begin{array}{l}\text { n.a. } \\
0.5 \% \\
\text { n.a. } \\
99.5 \%\end{array}$ & $\begin{array}{r}4.8 \% \\
8.5 \% \\
54.9 \% \\
31.8 \%\end{array}$ & $\begin{array}{r}3.9 \% \\
2.0 \% \\
35.4 \% \\
58.7 \%\end{array}$ \\
\hline
\end{tabular}

Notes: fin. $=$ financial, opp. $=$ opportunity, n.a. $=$ not applicable

However, as long as the total number of infected people treated is accepted as a useful indicator of effectiveness, PTT is potentially the most costeffective option. And clearly it would also be possible for the programme to extend the option to the entire District if the extra expenditure was judged worthwhile.

The percentage distribution of costs by input category and by type of activity is found in Table 3. This information is useful for managers seeking to introduce economies into the system, and is a valuable part of the cost menu. It is also useful for considering which items should be included in a sensitivity analysis, illustrated with respect to drug costs.

Praziquantel accounts for the largest proportion of costs for both MMT (83.5\%) and PTT $(58.1 \%)$, and is second only to supplies such as reagent strips in RST. The price, however, has been falling in recent years and Figure 1 shows that further reductions would not only reduce the total financial costs of each option, but could alter the relative attractiveness of MMT and RST. If drug costs were reduced by more than $67 \%$, MMT would become more affordable than RST, and would, with its greater effectiveness, be a more attractive option. Figure 2 illustrates this by considering the effect of falling drug costs on the cost per infected person treated under each approach. A reduction in drug costs of more than $30 \%$ would make MMT more efficient than RST.
However, these figures also show that PTT remains the most cost-effective option even if drug costs are reduced by $100 \%$, i.e. if praziquantel were provided free. Although these figures are based on changes in financial costs, the conclusions do not alter when economic costs are considered. Accordingly, for any realistic price of praziquantel, PTT remains the option of choice.

\section{Discussion}

The total costs of an intervention indicate affordability. Tanzania's annual governmental health expenditure was US\$ 27 million in 1991/2, and based on an approximate population of 22 million, annual per capita expenditure was US\$ 1.20. Although not directly comparable, the financial cost per capita of MMT, RST and PTT of US\$ $0.08,0.05$ and 0.11 in turn, are well below actual per capita government health expenditures. Certainly, the estimates here of cost per capita and cost per infected person treated (see Table 2) are much lower than previous estimates of schistosomiasis control options (Evans 1992; Guyatt and Evans 1992), and being more affordable, are more likely to be sustainable.

The strong conclusion that PTT is both affordable and the most cost-effective option is to some extent dependent on the outcome measure used to assess effectiveness. In this analysis the number of infected persons treated, adults plus 


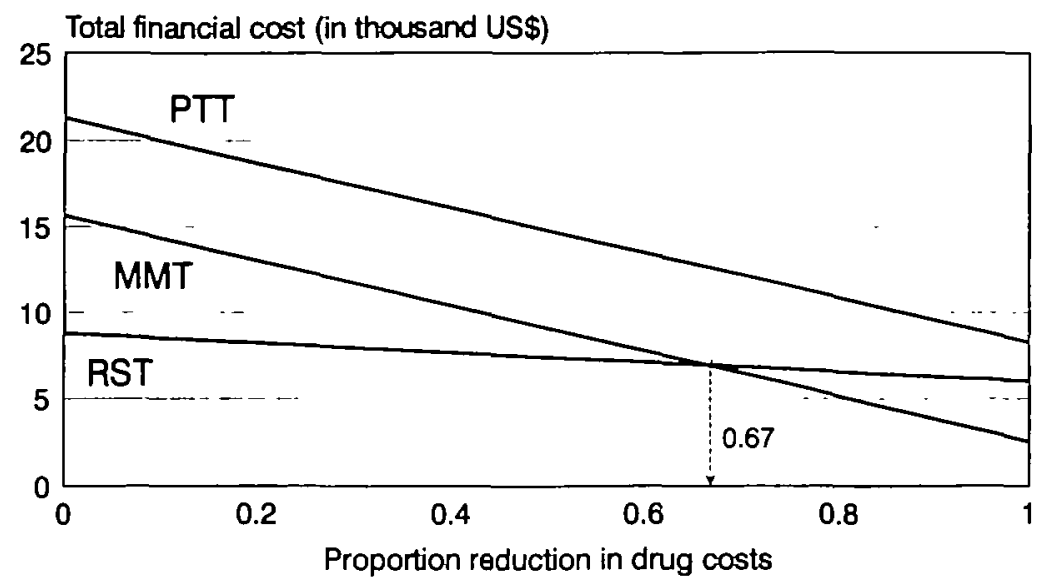

Figure 1. The effect of reducing drug costs on the total financial cost of each control option

The total economic costs produce similar patterns, though the threshold drug reduction required to change the ranking of RST and MMT is lower (0.65).

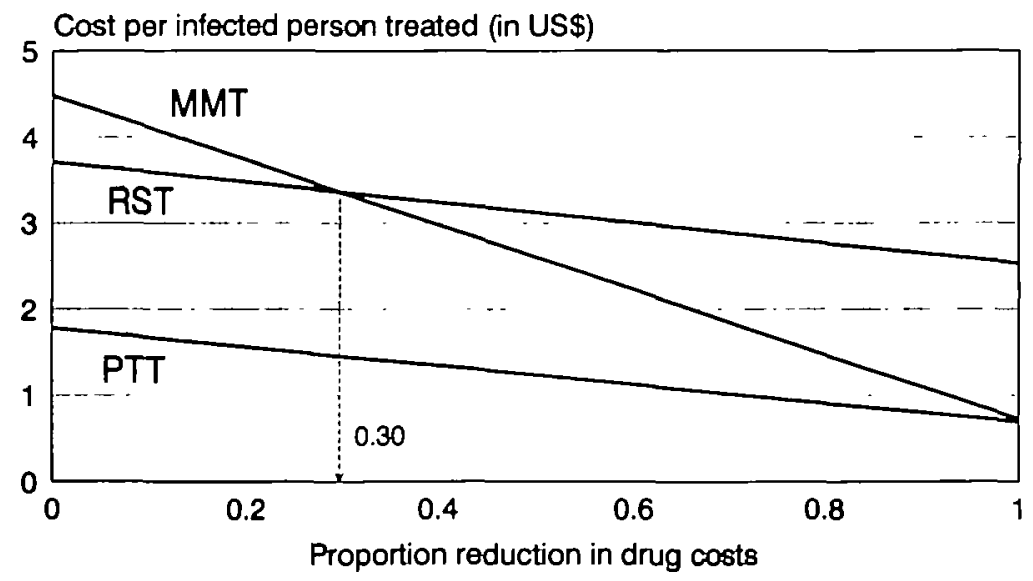

Figure 2. The effect of reducing drug costs on the cost per infected person treated

The casts in this figure represent financial casts only. The total economic costs produce similar patterns, though the threshold drug reduction required to change the ranking of RST and MMT is lower (0.27).

children, was used as the indicator of effectiveness. If, however, the reduction in morbidity resulting from treating one child were greater than that for treating one adult, the results overstate the relative attractiveness of PTT compared to RST and MMT. Nevertheless, at the extreme, when effectiveness is measured only as the number of infected children treated, PTT remains the most cost-effective option.
Clearly, adults suffer chronic morbidity, but the impact of treatment on this is not clear, nor is the relative benefit of treating adults compared to children. A more appropriate outcome measure would be the reduction in morbidity itself, measured over more than one time period. This would require a dynamic approach to the calculations, perhaps following the approach taken with the intestinal nematodes (Guyatt et al. 
1993; Medley et al. 1993). A dynamic model might also expose the fact that while PTT results in treatment throughout the year, the school-based approaches result in relatively simultaneous treatment across communities, perhaps with different effects on the dynamics of transmission. We are currently working on the extension of the nematode models to schistosomiasis, but to date no direct indicator of morbidity which can be used in cost-effectiveness studies of schistosomiasis control options is available, even for static models (Guyatt and Evans 1992).

The percentage distribution of input costs is useful to indicate which items constitute the highest expense, and thus which areas have a large potential for savings. In this analysis, drug costs constituted a large proportion of the total costs for MMT and PTT, but less so for RST. This has important implications as a continued fall in the price of praziquantel can influence the ranking of alternatives as well as their affordability. It is also possible that the unit cost of reagent strips may be reduced in the near future, perhaps by as much as three-quarters. This would further favour the cost-effectiveness of RST over MMT at current drug prices. In contrast, personnel costs constituted only a small proportion of total costs, thus savings made by factors such as increased worker productivity are likely to have little effect on the overall cost of the programme.

Since some of the procedures for measuring costs and outcomes involve estimates or assumptions, it is necessary to assess whether variations in these assumptions change the conclusions. For reasons of clarity, the only sensitivity analysis undertaken for this paper involved a reduction in drug costs. Further sensitivity analysis is the subject of continuing work. Particularly pertinent will be variations in compliance rates for treatment and screening, and diagnostic sensitivity and specificity. The itemized framework that has been developed permits variations in unit costs and economic, demographic and epidemiological parameters to be considered in a manner that allows application to other endemic areas.

Whatever control measure is chosen it is important that changes in infection and morbidity as a result of intervention are monitored through time, as a fall in levels of endemicity may have a dramatic effect on the cost-effectiveness of the chosen approach. The analysis presented here strongly suggests that the use of existing primary health care services can be an affordable and cost-effective approach to schistosomiasis control. However, the possible value of special vertical-type programmes in some instances should not be ignored. For example, mass treatment by a mobile team may be highly costeffective in areas of high endemicity and high focality. Accordingly, further analyses are being undertaken on a combination of approaches within this District - for instance, mass treatment by a mobile team in areas of high endemicity and high focality, and PTT in areas of lower endemicity.

This, however, implies that highly endemic villages can be identified relatively cheaply. The availability of rapid, inexpensive methods of identifying high-risk areas for $S$. haematobium through questionnaires (Lengeler et al. 1991a,b; 1992) is a possible solution and a two-step strategy for the attack phase of a control programme may prove feasible. In the first step the questionnaire could be used to identify high and low risk areas, and the second step would involve implementing the most feasible and costeffective option for control in each type of area. This is the subject of ongoing research.

\section{References}

Brinkmann UK, Werler C, Traore $M$ and Korte R. 1988. The costs of schistosomiasis control in a Sahelian country. Tropical Medicine and Parasitology 39: 175-82.

Bundy DAP and Guyatt HL. 1992. Cost analysis of schistosomiasis. Transactions of the Royal Society of Tropical Medicine and Hygiene 86: 646-8.

Evans D. 1992. Economics and tropical diseases: a research agenda using schistosomiasis as an example. Southeast Asian Journal of Tropical Medicine and Public Health 23: 641-6.

Gilson L. 1992. Value for money? The efficiency of primary health care units in Tanzania. PhD thesis, London School of Tropical Medicine and Hygiene, UK.

Gryseels B. 1989. The relevance of schistosomiasis for public health. Tropical Medicine and Parasitology 40: 134-42.

Guyatt HL and Evans D. 1992. Economic considerations for helminth control. Parasitology Today 8: 397-402.

Guyatt HL, Bundy DAP and Evans D. 1993. A population dynamic approach to the cost-effectiveness analysis of mass anthelmintic treatment: effects of treatment frequency on Ascaris infection. Transactions of the Royal Society of Tropical Medicine and Hygiene 87: 570-5. 
Jobin WR. 1989. The economics of bilharzia control. In: Miller MJ and Love EJ (eds). Parasitic Diseases: Treatment and Control. Florida, CRC Press.

Korte R, Schmidt Ehry B, Kielmann AA and Brinkmann UK. 1986. Cost and effectiveness of different approaches to schistosomiasis control in Africa. Tropical Medicine and Parasitology 37: 149-52.

Lengeler C. 1989. Individual and community diagnosis of urinary schistosomiasis and their relevance for disease control; a study in an endemic area of southeastern Tanzania. PhD thesis, University of Basel.

Lengeler $C$, de Savigny D, Mshinda $H$, Mayombana $C$, Tayari S, Hatz C, Degremont A and Tanner M. 1991a. Community-based questionnaires and health statistics as tools for the cost-efficient identification of communities at risk of urinary schistosomiasis. International Journal of Epidemiology 20: 796-807.

Lengeler $\mathrm{C}$, Kilima $\mathrm{P}$, Mshinda $\mathrm{H}$, Morona D, Hatz $\mathrm{C}$ and Tanner M. 1991b. Rapid low-cost, two-step method to screen for urinary schistosomiasis at district level: the Kilosa experience. Bulletin of the World Health Organisation 69: 179-89.

Lengeler C, Komba S and Morona D. 1991c. Urinary schistosomiasis: influence of the circadian variation of hematuria and proteinuria on reagent strip testing. Acta Tropica 48: 313-7.

Lengeler C, Sala-Diakanda DM and Tanner M. 1992. Using questionnaires through an existing administrative system: a new approach to health interview surveys. Health Policy and Planning 7: 10-21.

Medley GF, Guyatt HL and Bundy DAP. 1993. A quantitative framework for evaluating the effect of community treatment on the morbidity due to ascariasis. Parasitology 106: $211-21$.

Prescott NM. 1987. The economics of schistosomiasis chemotherapy. Parasitology Today 3: $21-4$

Reynolds J and Gaspari KC. 1985. Operations research methods: cost-effectiveness analysis. Primary Health Care Operations Research monograph series no. 2. Center for Human Services, Chevy Chase, Maryland.

Rohde R. 1989. Schistosomiasis control: an estimation of costs. Tropical Medicine and Parasitology 40: 240-4.

Tanner M. 1989. From the bench to the field: control of parasitic infections within primary health care. Parasitology 99: 581-92.

Tanner $M$, Degremont A, de Savigny D, Freyvogel TA, Mayombana $C$ and Tayari S. 1987. Longitudinal study on the health status of children in Kikwawila village, Tanzania. Acta Tropica 44: 119-37.

Tanner M, de Savigny D, Mayombana C, Hatz C, Burnier E, Tayari S and Degremont A. 1991. Morbidity and mortality at Kilombero, Tanzania, 1982-88. In: Feachem RG \& Jamison DT (eds). Disease and Mortality in Sub-Saharan Africa. Oxford University Press, Oxford.

\section{Acknowledgements}

The authors would like to thank the District Medical Officers of Kilombero (Dr S Tayari) and Kilosa (Dr B Mdalangwila), the District Educational Officers of Kilombero (Mr E Ngonyani and L J Mtolera) and Kilosa (Mr Kisongela) and members of the Communicable Disease Control project (Ifakara Centre, Tanzania) for contributing to the collection of the data on which this analysis was based. We would also like to thank Lucy Gilson, Hassan Mshinda and Thomas Teuscher (Head, Ifakara Centre) for useful discussions and Bruno Gryseels for his comments on the manuscript. We also thank Professor W L Kilama, Director General, National Institute for Medical Research, for the support of the study. Research clearance was granted by the Tanzanian Commission for Science and Technology as per reference RA 47/307.

Financial support was provided by grants from the Swiss Development Cooperation. Helen Guyatt is in receipt of a Wellcome Trust Travelling Research Fellowship and Christian Lengeler was supported by the 'Rudolf Geigy Stiftung zu Gunsten des Schweizerischen Tropeninstituts'. The opinions expressed in the paper are those of the authors and not necessarily those of the institutions they represent.

\section{Biographies}

Helen Guyatt, BSc, PhD (Imperial College, London), is an epidemiologist currently working at the Swiss Tropical Institute (Basel, Switzerland) where she is in receipt of a Wellcome Trust Travelling Research Fellowship to investigate the cost-effectiveness of different methods of helminth control, in particular those focused at schistosomiasis.

David Evans, $\mathrm{PhD}$, is a health economist with the Social and Economic Research component of the UNDP/WORLD BANK/WHO Special Programme for Research and Training in Tropical Diseases.

Christian Lengeler, MSc, PhD, worked on the seroepidemiology of alveolar echinococcosis in Switzerland between 1984 and 1985 . He was subsequently a research assistant at the Swiss Tropical Institute field laboratory in Ifakara, Tanzania, where he worked on the diagnosis of schistosomiasis and other parasitic diseases. In 1990, he acted as technical advisor to the TDR/SER study on the rapid assessment of schistosomiasis in 7 African countries. After completion of an MSc in Epidemiology, he joined the Tropical Epidemiology Unit of the London School of Hygiene and Tropical Medicine.

Marcel Tanner, BSc, MSc (Basel), MSc (CHDC, London), PhD (Basel), is head of the Department of Public Health and Epidemiology at the Swiss Tropical Institute, Basel, Switzerland, and Professor of Tropical Public Health at the University of Basel. After laboratory-based research on the immunology of filariasis and the in-vitro cultivation of trypanosomes, he conducted epidemiological, operational and health systems research in various African countries (mainly Cameroon, Chad, Liberia and Tanzania) for the last 12 years. Besides his research interests and teaching commitments in the field of epidemiology and public health, he directs major health service development cooperation programmes in rural and urban regions of Chad and Tanzania.

Correspondence: Dr Helen Guyatt, Department of Public Health and Epidemiology, Swiss Tropical Institute, Socinstrasse 57, $\mathrm{CH}-4002$ Basel, Switzerland. 